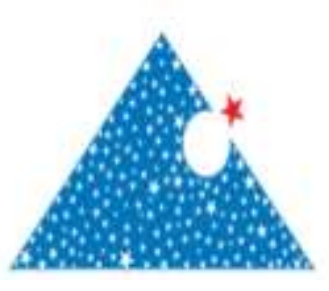

\title{
Genleştirilmiş Cam Agregalı ve Genleştirilmiş Perlit Agregalı Şap Harçlarının Performans Özelliklerinin Belirlenmesi
}

\author{
Yusuf Tahir ALTUNCI ${ }^{1 a^{*}}$, Cenk ÖCAL ${ }^{2 b}$, Kemal SAPLIOĞLU $^{3 c}$, Hüseyin Hakan İNCE ${ }^{4 d}$, \\ Murat ÇEVIKKBAŞ ${ }^{2 \mathrm{e}}$
}

\begin{abstract}
${ }^{1}$ Isparta Uygulamalı Bilimler Üniversitesi, Teknik Bilimler MYO, İnşaat Bölümü, Isparta/TÜRKIYE, ${ }^{2}$ Isparta Uygulamalı Bilimler Üniversitesi, Teknoloji Fakültesi, İnşaat Mühendisliği Bölümü, Isparta/TÜRKIYYE, ${ }^{3}$ Süleyman Demirel Üniversitesi, Mühendislik Fakültesi, İnşaat Mühendisliği Bölümü, Isparta/TÜRKIYE, ${ }^{4}$ Burdur Mehmet Akif Ersoy Üniversitesi, Mühendislik-Mimarlık Fak., İnşaat Müh. Bölümü, Burdur/TÜRKIYE, yusufaltunci@isparta.edu.tr
\end{abstract}

Received/Geliş: 16.06 .2020

Accepted/Kabul: 05.10.2020

\begin{abstract}
Öz: Bu çalışmada yüzey kaplama ve tesviye amacı ile kullanılan şap harcı üretiminde genleştirilmiş cam agregası ve genleştirilmiş perlit agregası kullanarak şap harçları üretilmiş ve şap harcı malzemesinin birim hacim ağırlığının azaltılması, 1Sı ve ses izolasyon performanslarının arttırılması hedeflenmiştir. Bu amaçla inşaat sektöründe yaygın olarak kullanılan 4 tip çimento kullanılarak, genleştirilmiş cam agregası $(0.25-0.5 \mathrm{~mm})$ ve genleştirilmiş perlit agregası $(0.25-0.5 \mathrm{~mm})$, CEN standart kumu yerine $\% 0, \% 15$ ve $\% 30$ oranlarında ikame edilmiştir. Elde edilen ikameli şap numunelerinde yoğunluk, 1sı ve ses izolasyon performans özellikleri deneyler ile belirlenmiştir. Bu deneylerde TS EN 13892-1 standardına göre şap harçları üretilmiş ve TS EN 13813 standardına göre çimento esaslı şap harçlarında belirlenmesi zorunlu olan basınç dayanımı, eğilme dayanımı ve aşınma direnci deneyleri yapılmıştır. Çalışmanın sonucunda; $17.60 \mathrm{MPa}-58.00 \mathrm{MPa}$ basınç dayanımı aralığında, 4.00 MPa-11.16 MPa eğilme dayanımı aralığında, $9.22 \mathrm{~cm}^{3} / 50 \mathrm{~cm}^{2}-17.26 \mathrm{~cm}^{3} / 50 \mathrm{~cm}^{2}$ aşınma direnci aralığında, $1.669 \mathrm{~g} / \mathrm{cm}^{3}-2.192 \mathrm{~g} / \mathrm{cm}^{3}$ yoğunluk aralığında, 0.151-0.249 ses yutma katsayısı aralığında ve $0.446 \mathrm{~W} / \mathrm{mK}-0.817$ $\mathrm{W} / \mathrm{mK}$ 1sıl iletkenliği aralığında, genleştirilmiş cam agregalı ve genleştirilmiş perlit agregalı şap harçlar elde edilmiş olup şap harçlarının ilgili parametreler ile olan ilişkisi irdelenmiştir.
\end{abstract}

Anahtar Kelimeler: Genleştirilmiş cam; genleştirilmiş perlit; şap harc1.

\section{Determination of Performance Characteristics of Screed Mortar with Expanded Glass Aggregate and Expanded Perlite Aggregate}

\begin{abstract}
In this study, it is aimed to reduce the density of the screed mortar and increase the heat and sound performance of the screed by using expanded glass aggregate and expanded perlite aggregate in screed mortar which is mainly used for surface coating and leveling in the construction sector. To achieve this objective, the most common four cement types in the construction industry were used, and expanded glass aggregates $(0.25-0.5$ $\mathrm{mm})$ and expanded perlite aggregates $(0.25-0.5 \mathrm{~mm})$ were replaced with CEN standard sand as the ratio of $0 \%$, $15 \%$ and $30 \%$. The density, heat and sound insulation performance properties of the substituted screed samples obtained were obtained through experiments. In these experiments, screed mortars were produced in accordance with TS EN 13892-1 standard, and tests concerning compressive strength, bending strength and wearing resistance, which were required to be determined in cement-based screed mortars according to TS EN 13813 standard were performed. In the light of the study; expanded glass aggregates and expanded perlite aggregates were used to obtain screed mortar with the strength range between 17.60 MPa and $58.00 \mathrm{MPa}$, bending strength range between $4.00 \mathrm{MPa}$ and $11.16 \mathrm{MPa}$, wearing resistance range between $9.22 \mathrm{~cm}^{3} / 50 \mathrm{~cm}^{2}$ and $17.26 \mathrm{~cm}^{3} /$ $50 \mathrm{~cm}^{2}$, density range between $1.669 \mathrm{~g} / \mathrm{cm}^{3}$ and $2.192 \mathrm{~g} / \mathrm{cm}^{3}$, sound absorption range between 0.151 and 0.249 , thermal conductivity range between $0.446 \mathrm{~W} / \mathrm{mK}$ and $0.817 \mathrm{~W} / \mathrm{mK}$, and the related parameters were examined.
\end{abstract}

Keywords: Expanded glass; expanded perlite; screed mortar. 


\section{Giriş}

Kullandığımız enerji miktarı her geçen gün artmakta ve bu artış ülke ekonomilerine büyük zararlar vermektedir [1]. Bununla birlikte enerji kaynaklarına olan talebin artmasına da neden olmaktadır [2]. Ülkemizde kullanılan elektrik enerjisinin \%70'inin dışa bağımlı olması ve fosil kaynaklı yakıtların bir gün tükenecek olması enerji tasarrufu için alınabilecek önlemleri gündeme getirmiştir [3]. Enerjinin tasarrufu ile ilgili olarak 05.12.2009 tarihinden itibaren yürürlüğe giren "Binalarda Enerji Performans Yönetmeliği" [4] çerçevesinde enerji verimliliği yüksek yapı malzeme ve elemanlarına ihtiyaç duyulması ülkemiz için son derece önemli bir konu olmuştur. Aynı zamanda “'Binaların Gürültüye Karşı Korunması Yönetmeliği' [5], 31.05.2018 tarihinden itibaren yürürlüğe girmiştir. Bu yönetmelik ile birlikte, konut içerisinde yürüme gibi darbe ile yayılan sesin iletimini engellemek için döşemeler belirli koşulları sağlamak zorunda olup, yapılan düzenleme ile yalıtım zorunluluk haline gelmiştir [6].

Dünyada ve ülkemizdeki teknolojik gelişmeler, artan şehir nüfus oranlarına paralel olarak enerjinin daha çok kullanımını artırmakta ve enerji alanında da olumlu gelişmeler meydana gelmektedir [3]. Yapı malzemesi sektöründeki firmalar sadece en iyi kalite, en geniş çeşitlilik ve en iyi fiyat için rekabet etmeyip aynı zamanda sürdürülebilir kalkınma, kurumsal sosyal sorumluluk ve çevrenin korunması için de birbirleriyle daha fazla rekabet etmek durumunda kalmaktadırlar [7]. Bu gelişmelerden dolayı; perlit kayacının, ısıl işleme maruz bırakılması sonucu elde edilen genleştirilmiş perlit gibi malzemelerin yanında; yalıtım özelliği fazla, uzun ömürlü, geri dönüştürülmüş cam maddelerin 1sıl işleme maruz bırakılması sonucu elde edilen genleştirilmiş cam gibi sürdürülebilir yapı malzemelerinin piyasaya çıkarılması büyük önem taşımaktadır [1]. Avrupa piyasasında uzun yıllardan beri hafif beton üretiminde [7,8,9-10] kullanılan bu malzemelerin, farkl1 yapılar oluşturmaya oldukça elverişli yapısı sayesinde, diğer beton türlerinde de yaygın olarak kullanılması beklenmektedir. $\mathrm{Bu}$ amaçla, görsel güzellik ve özel kullanım amacı yanında genleştirilmiş cam agregası ve genleştirilmiş perlit agregası kullanarak yalıtım özellikleri geliştirilmiş, şap harcı adı verilen modern zemin kaplama malzemelerine her zaman ihtiyaç duyulmaktadır. Genleştirilmiş cam agregasının ve genleştirilmiş perlit agregasının; artan termal kararlılık, artan tokluk gibi büyük avantaj sağlayan özelliklerinden dolayı şap harcı üretiminde kullanılması performans ve ekonomiklik açısından önemlidir [1]. Bu kapsamda değerlendirildiğinde; genleştirilmiş cam ve genleştirilmiş perlit dayanıklılığının yanı sıra düşük yoğunluklu olması, 1s1 ve ses yalıtımını iyileştirmesi gibi avantajlara sahiptir [11,12]. Genleştirilmiş cam agreganın hacmi, atık camın hacminden yaklaşık olarak 17 kat daha fazladır ve bu özelliğinden dolayı suda batmayan beton kano yapımında da kullanılmaktadır [13,14]. Genleştirilmiş cam agregalar $16 \mathrm{~mm}$ tane boyutuna kadar üretilmektedir [12,15,16,17-18]. Ancak betonda iri agrega olarak kullanımı beton mukavemetini çok düşürmesi [7,8-19] sebebiyle tercih edilmediği için 4 mm'ye kadar olan cam agregalar sektörde daha çok kullanılmaktadır [20,21]. Bunun yanında ülkemizin volkanik kesimlerinde bolca bulunan perlit kayacı, yüksek isıl işlemlere maruz bırakıldığında, hacminin 20 katına kadar genişleyerek yükssek termal özelliğe, düşük birim hacim ağırlığa, fiziksel esnekliğe, kimyasal sabitliğe ve yangına dayanıklı bir yapıya dönüşerek [11,22]; izolasyon malzemelerinde, sıvalarda, yalıtım betonlarında, hafif yapı elemanlarında, gevşek dolgu gerektiren yerlerde, yüzey döşemelerinde ve farklı bağlayıcılarla yapılan özel amaçlı perlit betonlarında yapı malzemesi olarak yaygın bir biçimde kullanılmaktadır [11]. Literatürde, perlitli, genleştirilmiş perlitli, cam lif katkılı ve genleştirilmemiş cam ikameli harçlar ve betonlar hakkında sayısız çalışma bulunmakta, fakat şap harcı üretiminde, genleştirilmiş camın ve genleştirilmiş perlitin agrega olarak kullanılması ile birim hacim ağırlığının azaltıldığg1, ssıl iletkenlik değerlerinin ve ses yutma katsayısı özelliklerinin incelendiği bir çalışma bulunmamaktadır [1].

$\mathrm{Bu}$ çalışmada, şap harcı üretimlerinde, genleştirilmiş cam agregası ve genleştirilmiş perlit agregası CEN standart kumu yerine \%30 oranına kadar ikame edilerek TS EN 13892-1 standartı [23] kapsamında şap harcının birim hacim ağırlığının azaltılması, ısı ve ses izolasyon performanslarının 
artırılması hedeflenmiştir. $\mathrm{Bu}$ sebeple bu çalışma kapsamında, inşaat sektöründe yaygın olarak kullanılan 4 tip çimento (CEM I 42.5 R, CEM I $52.5 \mathrm{~N}$, CEM II 42.5 R ve CEM IV $32.5 \mathrm{~N}$ ) ile genleştirilmiş cam ve genleştirilmiş perlit agregalarını CEN standart kumu yerine \%0, \%15 ve \%30 oranlarında ikame ederek şap harçları üretilmiş; TS EN 13813 standardına [24] göre yapılan sertleşmiş şap harcı mekanik özelliklerine (eğilme dayanımı, basınç dayanımı ve aşınma direnci deneyleri) ek olarak yoğunluk, ısıl iletkenlik ve ses yutma katsayısı değerleri belirlenmiştir. Bu çalışma ile genleştirilmiş cam agregalı şap harçlarının ve genleştirilmiş perlit agregalı şap harçlarının performans özellikleri belirlenmiş olup, bu malzemelerin inşaat sektöründe kullanılabilirliği irdelenmiştir. Buna ek olarak genleştirilmiş camların geri dönüşümü ile de hem çevresel hem de endüstriyel yönden katkı sağlanmıştır.

\section{Materyal ve Metot}

\subsection{Materyal}

Deneysel çalışmalarda; CEM I $42.5 \mathrm{R}$ portland çimento [25], CEM I $52.5 \mathrm{~N}$ portland çimento [26], CEM II/A-M (P-LL) $42.5 \mathrm{R}$ portland kompoze çimento [27] ve CEM IV/B (P) $32.5 \mathrm{~N}$ puzolanik çimento türleri [28] ile $2.56 \mathrm{~g} / \mathrm{cm}^{3}$ yoğunluğundaki CEN standart kumu, 0.25-0.5 mm elek çapı aralığındaki ve $0.38 \mathrm{~g} / \mathrm{cm}^{3}$ yoğunluğundaki genleştirilmiş cam granülleri [29] ve $0.25-0.5 \mathrm{~mm}$ elek çapı aralığındaki ve $0.15 \mathrm{~g} / \mathrm{cm}^{3}$ yoğunluğundaki genleştirilmiş perlit [22] kullanılmıştır.

Deneysel çalışmalarda kullanılan çimentoların, kimyasal, fiziksel ve mekanik özelikleri Tablo 1'de [25,26,27-28], CEN standart kumunun granülometrisi Tablo 2'de, genleştirilmiş cam granüllere ve genleştirilmiş perlite ait teknik bilgiler ise Tablo 3'de [22,29] verilmiştir.

Tablo 1. Deneysel çalışmalarda kullanılan çimentoların kimyasal, fiziksel ve mekanik özellikleri $[25,26,27-28]$

\begin{tabular}{|c|c|c|c|c|c|c|c|}
\hline \multirow[t]{2}{*}{ Çimento türü } & \multirow{2}{*}{$\begin{array}{l}\mathbf{C I}^{-} \\
(\%)\end{array}$} & \multirow{2}{*}{$\begin{array}{l}\mathrm{SO}_{3} \\
(\%)\end{array}$} & \multirow{2}{*}{$\begin{array}{l}\text { Priz basslama } \\
\text { (dakika) }\end{array}$} & \multirow{2}{*}{$\begin{array}{c}\text { Genleşme } \\
(\mathrm{mm})\end{array}$} & \multicolumn{3}{|c|}{ Basınç dayanımı (MPa) } \\
\hline & & & & & 2 günlük & 7 günlük & 28 günlük \\
\hline CEM I 42.5 R & 0.004 & 2.75 & 156 & 0.46 & 24.3 & ---- & 50.1 \\
\hline CEM I 52.5 N & 0.0008 & 2.59 & 140 & 0 & 30.2 & ---- & 54.9 \\
\hline $\begin{array}{l}\text { CEM II/A-M } \\
\text { (P-LL) 42.5 R }\end{array}$ & 0.012 & 2.77 & 139 & 0.36 & 23.9 & --- & 48.1 \\
\hline $\begin{array}{l}\text { CEM IV/B } \\
\text { (P) } 32.5 \mathrm{~N}\end{array}$ & 0.013 & 2.80 & 143 & 0.35 & --- & 25 & 36.6 \\
\hline
\end{tabular}

Tablo 2. CEN standart kumun granülometrisi [1]

\begin{tabular}{lcccccc}
\hline Kare göz açıklığı (mm) & $\mathbf{2 . 0 0}$ & $\mathbf{1 . 6 0}$ & $\mathbf{1 . 0 0}$ & $\mathbf{0 . 5 0}$ & $\mathbf{0 . 1 6}$ & $\mathbf{0 . 0 8}$ \\
Kümülatif elekte kalan (\%) & 0 & $8 \pm 2$ & $34 \pm 2$ & $66 \pm 2$ & $7 \pm 2$ & $99 \pm 1$ \\
\hline
\end{tabular}

Tablo 3. Genleştirilmiş cam granüllere ve genleştirilmiş perlite ait teknik bilgiler [22,29]

\begin{tabular}{lcccc}
\hline & $\begin{array}{c}\text { Yoğunluk } \\
\left(\mathbf{g} / \mathbf{c m}^{\mathbf{3}}\right)\end{array}$ & $\begin{array}{c}\text { Su emme } \\
(\mathbf{\%})\end{array}$ & $\begin{array}{c}\text { Yumuşama noktası } \\
\left({ }^{\circ} \mathbf{C}\right)\end{array}$ & $\begin{array}{c}\text { pH değeri } \\
(\mathbf{p H})\end{array}$ \\
\hline Genleştirilmiş cam & $0.37 \pm 0.04$ & 17 & 700 & $8-11$ \\
Genleştirilmiş perlit & $0.032-0.18$ & $200-600$ & $871-1093$ & 6.8 \\
\hline
\end{tabular}

\subsection{Metot}

Şap harçları ağır bir yapı malzemesi olup, 1sı ve ses izolasyon performansları sıklıkla önemsenmemektedir. Bu çalışmada yüzey kaplama ve tesviye amacı ile kullanılan şap harcı 
üretiminde CEM I 42.5 R [25], CEM I 52.5 N [26], CEM II 42.5 R [27] ve CEM IV 32.5 N [28] çimento türleri ile genleștirilmiş cam agregası $(0.25-0.5 \mathrm{~mm})$ [29] ve genleştirilmiş perlit agregası $(0.25-0.5 \mathrm{~mm})$ [22], CEN standart kumu yerine $\% 0, \% 15$ ve $\% 30$ oranlarında hacimce ikame edilerek genleştirilmiş cam agregalı ve genleştirilmiş perlit agregalı şap harcı numuneleri TS EN 13892-1 Şap Malzemeleri - Deney Metotları - Bölüm 1: Deneyler İçin Numune Alma, Hazırlama ve Kürleme (2004) standardına göre üretilmiş [23] ve üretilen numuneler TS EN 196-1 (2016) standardına göre kalıplara yerleştirilmiştir [30]. Numuneler 1 gün sonra kalıptan çıkartılarak, kür havuzlarına konulmuştur. Üretilen sertleşmiş şap harcı örneklerine ait bazı görseller Şekil 1'de verilmiştir.

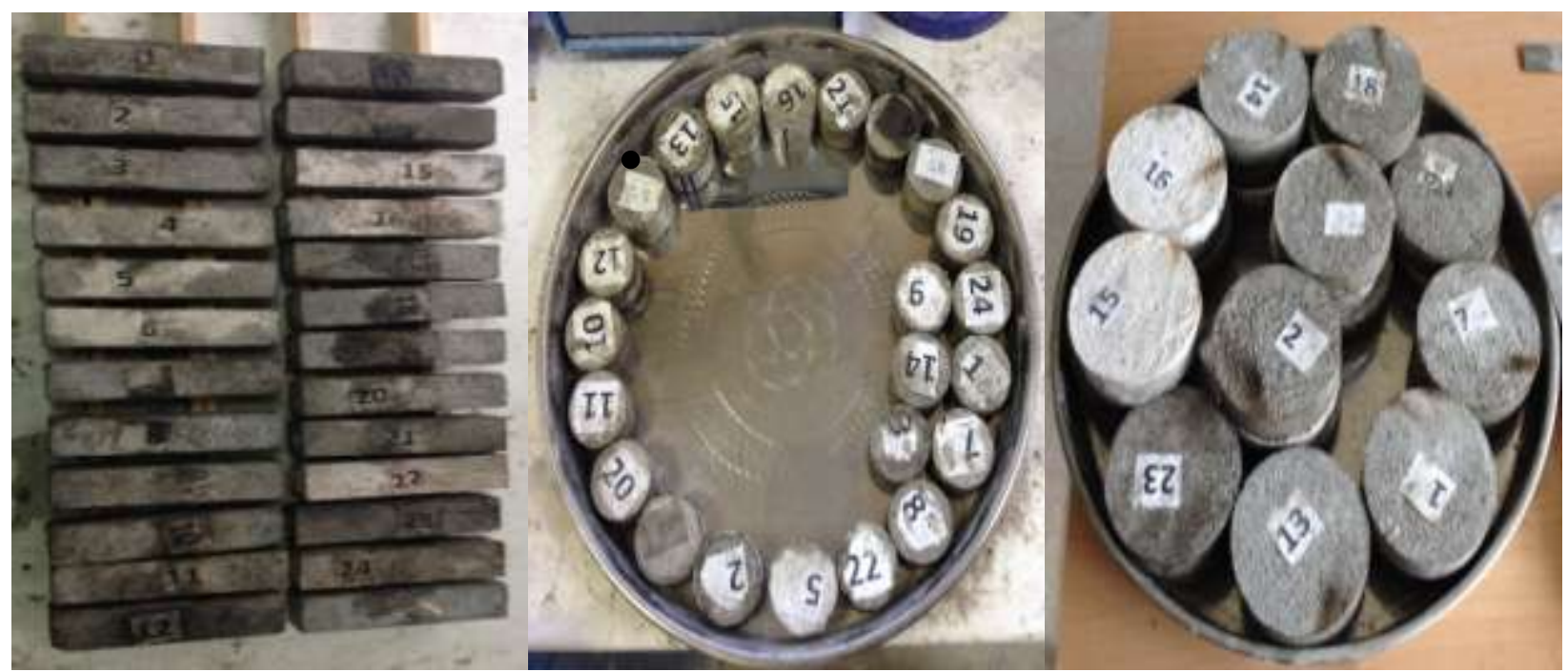

Şekil 1. Üretilen sertleşmiş şap harcı örneklerine ait bazı görseller [1]

Süresi gelen ve yapılacağı deney önceden belirlenen numuneler kür havuzundan çıkartılarak, TS EN 13813 standardına [24] göre çimento esaslı şap harçlarına yapılması zorunlu olan; TS EN 196-1 (2016) standardına göre eğilme dayanımı ve basınç dayanımı deneyleri [30] ile TS EN 13892-3 (2015) standardına göre Böhme aşınma direnci deneyine [31] tabi tutulmuş, daha sonra bu deneylere ek olarak TS EN 12390-7 (2010) standardına göre yoğunluk [32], TS EN ISO 10534-1 (2004) [33] ve TS EN ISO 10534-2 (2003) [34] standardına göre ses yutma katsayıs1 deneyleri ve TS EN 12664 (2009) standardına göre 1sıl iletkenlik deneyleri [35] yapılarak şap harcı malzemesinin birim hacim ağırlığının azaltılması, 1Sı ve ses izolasyon performanslarının arttırılması hedeflenmiştir. Kullanılan kodlamaya ait detaylı bilgilendirme ise Tablo 4'de belirtilmiştir.

Tablo 4. Genleştirilmiş cam agregalı ve genleştirilmiş perlit agregalı şap harçlarına ait kodlama detayları

\begin{tabular}{cccc}
\hline Kullanılan çimento türü & Kodlama ilk 2 hanesi & Çimento türü & Kodlama 3. Hanesi \\
\hline CEM I & CI & 32.5 & $\mathrm{~A}$ \\
CEM II & CII & 42.5 & $\mathrm{~B}$ \\
CEM IV & CIV & 52.5 & $\mathrm{C}$ \\
\hline Genleştirilmiş cam ve & Genleştirilmiş cam için & Genleştirilmiş̧ perlit için kodlamanın \\
genleştirilmiş perlit ikame & kodlamanın sonraki 3 veya & sonraki 3 veya 4 hanesi \\
oranı & 4 hanesi & \\
\hline$\% 0, \% 15$ ve \%30 & EG, 15EG ve 30EG & EP, 15EP ve 30EP
\end{tabular}

Örneğin CIB15EG kodu, CEM I 42.5 çimentosu kullanılarak ve CEN standart kum yerine \%15 genleştirilmiş cam agrega ikame edilerek üretilen örneği ifade etmektedir. Çalışma süresince yapılan deneysel çalışmalar ise Tablo 5'de özetlenmiştir. 
Tablo 5. Çalışma süresince yapılan deneysel çalışmalar ve ilgili standartlar

\begin{tabular}{|c|c|}
\hline Yapılan Deney & İlgili Standart \\
\hline Sertleşmiş Harç & TS EN 12390-7. (2010). Beton - Sertleșmiș Beton Deneyleri - Bölüm 7: Sertleșmiş \\
\hline Yoğunluk & Beton Yoğunluğunun Tayini. Türk Standartları, Ankara [32]. \\
\hline Eğilme ve Basınç & TS EN 196-1. (2016). Çimento deney metotları - Bölüm 1: Dayanım tayini. Türk \\
\hline Dayanımı & Standartları, Ankara [30]. \\
\hline Böhme Aşınma & TS EN 13892-3. (2015). Şap Malzemeleri - Deney Yöntemleri - Bölüm 3: Aşınma \\
\hline Direnci & Direncinin Tayini - Böhme. Türk Standartları, Ankara [31]. \\
\hline \multirow{2}{*}{$\begin{array}{l}\text { Ses Yutma } \\
\text { Katsay1s1 }\end{array}$} & $\begin{array}{l}\text { TS EN ISO 10534-1. (2004). Akustik- Empedans Borularında Ses Absorplama } \\
\text { Katsayısı ve Empedansın Tayini- Bölüm 1: Duran Dalga Oranını Kullanma Metodu. } \\
\text { Türk Standartları. Ankara [33]. }\end{array}$ \\
\hline & $\begin{array}{l}\text { TS EN ISO 10534-2. (2003). Akustik-Empedans Borularındaki Ses Absorpsiyon } \\
\text { Katsayısının Ve Empedansın Tayini-Bölüm 2: Aktarım Fonksiyonu Metodu. Türk } \\
\text { Standartları, Ankara [34]. }\end{array}$ \\
\hline Isıl İletkenlik & TS EN 12664. (2009). Yap1 Malzemeleri Ve Mamulleri- Isı1 Direncin, Korumalı \\
\hline Katsay1s1 & $\begin{array}{l}\text { Tablalı Isıtıcı ve Isı Akı Ölçerin Kullanıldı̆̆ı Metotlarla Tayini- Isıl Direnci Orta Ve } \\
\text { Düşük Seviyede Olan Kuru Ve Rutubetli Mamuller. Türk Standartları, Ankara [35]. }\end{array}$ \\
\hline
\end{tabular}

\section{Araştırma Bulguları}

\subsection{TS EN 13813 Standardı Kapsamında Yapılan Deneylerin Sonuçları (Eğime Dayanımı, Basınç Dayanımı Ve Aşınma Direnci Deneyleri)}

Genleştirilmiş cam agregalı ve genleştirilmiş perlit agregalı şap harçlarının mekanik özelliklerini belirlemek için; TS EN 196-1 (2016) [30] standardına göre yapılan 28 günlük eğilme ve basınç dayanımı deney sonuçları ve TS EN 13892-3 (2015) [31] standardına göre yapılan Böhme aşınma direnci deney sonuçları ve TS EN 13813 (2004) [24] standardına göre örneklerin özelliklerine göre kısa gösterimleri Tablo 6 ve Tablo 7'de verilmiştir.

Tablo 6. Genleştirilmiş cam agregalı şap harçlarına ait mekanik deney sonuçları ve TS EN 13813 standardına göre kısa gösterimi

\begin{tabular}{|c|c|c|c|c|}
\hline Numune & $\begin{array}{l}\text { Eğilme Dayanımı } \\
\text { (MPA) }\end{array}$ & $\begin{array}{l}\text { Basınç Dayanımı } \\
\text { (MPa) }\end{array}$ & $\begin{array}{c}\text { Böhme assınma } \\
\text { miktarı }\left(\mathrm{cm}^{3} / 50 \mathrm{~cm}^{2}\right)\end{array}$ & $\begin{array}{c}\text { TS EN } 13813 \text { (2004) } \\
\text { [24] Kısa gösterim }\end{array}$ \\
\hline$\overline{\text { CIB }}$ & 8.17 & 50.70 & 10.92 & CT-C50-F8-A10 \\
\hline CIB15EG & 7.42 & 45.56 & 12.18 & CT-C45-F7-A12 \\
\hline CIB30EG & 6.75 & 38.74 & 14.03 & CT-C38-F6-A14 \\
\hline CIC & 11.16 & 58.00 & 9.22 & CT-C58-F11-A9 \\
\hline CIC15EG & 10.71 & 48.40 & 11.13 & CT-C48-F10-A11 \\
\hline CIC30EG & 10.43 & 41.42 & 13.26 & CT-C41-F10-A13 \\
\hline CIIB & 7.45 & 50.30 & 11.01 & СТ-C50-F7-A11 \\
\hline CIIB15EG & 7.16 & 43.75 & 12.84 & CT-C43-F7-A12 \\
\hline CIIB30EG & 6.42 & 37.61 & 14.19 & CT-C37-F6-A14 \\
\hline CIVA & 4.60 & 37.30 & 14.54 & CT-C37-F4-A14 \\
\hline CIVA15EG & 4.48 & 28.17 & 15.63 & CT-C28-F4-A15 \\
\hline CIVA30EG & 4.17 & 20.27 & 16.08 & CT-C20-F4-A16 \\
\hline
\end{tabular}


Tablo 7. Genleştirilmiş perlit agregalı şap harçlarına ait mekanik deney sonuçları ve TS EN 13813 standardına göre kısa gösterimi

\begin{tabular}{lcccc}
\hline Numune & $\begin{array}{c}\text { Eğilme Dayanımı } \\
\text { (MPa) }\end{array}$ & $\begin{array}{c}\text { Basınç Dayanımı } \\
\text { (MPa) }\end{array}$ & $\begin{array}{c}\text { Böhme aşınma } \\
\text { miktarı }\left(\mathbf{c m}^{\left.\mathbf{3} / 50 \mathbf{c m}^{2}\right)}\right)\end{array}$ & $\begin{array}{c}\text { TS EN 13813 (2004) } \\
\text { [24] Kısa gösterim }\end{array}$ \\
\hline CIB & $\mathbf{8 . 1 7}$ & 50.70 & 10.92 & CT-C50-F8-A10 \\
CIB15EP & $\mathbf{7 . 0 1}$ & 42.70 & 13.06 & CT-C42-F7-A13 \\
CIB30EP & $\mathbf{6 . 4 4}$ & 35.63 & 14.55 & CT-C35-F6-A14 \\
& & & & \\
CIC & $\mathbf{1 1 . 1 6}$ & 58.00 & 9.22 & CT-C58-F11-A9 \\
CIC15EP & $\mathbf{1 0 . 7 7}$ & 44.20 & 11.94 & CT-C44-F10-A11 \\
CIC30EP & $\mathbf{1 0 . 4 7}$ & 38.95 & 13.85 & CT-C38-F10-A13 \\
& & & & \\
CIIB & $\mathbf{7 . 4 5}$ & 50.30 & 11.01 & CT-C50-F7-A11 \\
CIIB15EP & $\mathbf{6 . 8 1}$ & 42.40 & 13.15 & CT-C42-F6-A13 \\
CIIB30EP & 6.40 & 34.90 & 14.63 & CT-C34-F6-A14 \\
CIVA & 4.60 & 37.30 & 14.54 & CT-C37-F4-A14 \\
CIVA15EP & 4.42 & 26.95 & 15.79 & CT-C26-F4-A15 \\
CIVA30EP & 4.00 & 17.60 & 17.26 & CT-C17-F4-A17 \\
\hline
\end{tabular}

Tüm genleştirilmiş cam agregalı ve genleştirilmiş perlit agregalı şap harçları arasında en etkili basınç, eğilme ve aşınma özelliğine sahip örneklerin şahit örnekler olduğu, deney örnek gruplarının ve çimento türlerinin basınç dayanımı, eğilme dayanımı ve aşınmaya karşı direnç açısından sırasıyla CIC $>$ CIB $>$ CIIB $>$ CIVA ve EG $>$ EP şeklinde sıralandığı gözlemlenmiştir. Ayrıca yapılan deneyler sonucunda ikame oranı artışı ile basınç dayanımı, eğilme dayanımı ve aşınma direnci özelliklerinin olumsuzlaştığ 1 belirlenmiştir. Bu durum literatürde karışıma eklenen hafif agrega miktarı arttıkça, hafif agregalı betonların yoğunluklarının azaldığı ve dolayısıyla mekanik özelliklerinin olumsuz etkilendiği bilgisiyle örtüşmektedir [36,37-38]. Ayrıca genleştirilmiş cam agregalı örneklerin basınç dayanımı, eğilme dayanımı ve aşınma dirençlerinin genleştirilmiş perlit agregalı örneklerin aşınma dirençlerinden az da olsa daha etkili olduğu gözlemlenmiştir. Buradaki durum genleştirilmiş camın yoğunluğunun $\left(0.38 \mathrm{~g} / \mathrm{cm}^{3}\right)$ genleştirilmiş perlitin yoğunluğundan $\left(0.15 \mathrm{~g} / \mathrm{cm}^{3}\right)$ daha fazla olması ile açıklanabilir.

\subsection{TS EN 13813 Standartı Kapsamı Dışında Yapılan Deneylerin Sonuçları (Yoğunluk, Ses Yutma Katsayısı ve Isıl İletkenlik Deneyleri)}

Genleştirilmiş cam agregalı ve genleştirilmiş perlit agregalı şap harçlarının fiziksel özelliklerini belirlemek için; TS EN 12390-7 (2010) [32] standardına göre yapılan sertleşmiş yoğunluk deney sonuçları ve termal özelliklerini belirlemek için; TS EN ISO 10534-1 (2004) [33] ve TS EN ISO 10534-2 (2003) [34] standardına göre yapılan ses yutma katsayısı deney sonuçları ve TS EN 12664 (2009) [35] standardına göre yapılan ısıl iletkenlik deneyi sonuçları Tablo 8 ve Tablo 9'da verilmiştir.

Tüm genleştirilmiş cam agregalı ve genleştirilmiş perlit agregalı şap harçları arasında en yüksek ses yutma kapasitesine ve en düşük 1sıl iletkenlik değerine sahip örnek gruplarının ve çimento türlerinin sırasıyla $\mathrm{CIVA}>\mathrm{CIIB}>\mathrm{CIB}>\mathrm{CIC}$ ve $\mathrm{EP}>\mathrm{EG}$ şeklinde sıralandığı gözlemlenmiştir. Ayrıca yapılan deneyler sonucunda ikame oranı artışı ile örneklerin yoğunluklarının azalmasına bağlı olarak ses yutma kapasitelerinin arttığ sonuçlarının literatür bilgileri aralığında olması [36,39-40], üretmiş olduğumuz genleştirilmiş cam agregalı ve genleştirilmiş perlit agregalı şap harçlarının, yalıtımlı şap betonu uygulamalarında kullanılabileceğini göstermektedir. Ayrıca genleştirilmiş perlit agregalı örneklerin hem ses yutma 
kapasitelerinin hem de 1 sıl iletkenlik performanslarının genleştirilmiş cam agregalı örneklerinkinden az da olsa daha üstün olduğu gözlemlenmiştir. Bu yüzden yalıtım özelliklerinin ön plana çıtığ 1 yalıtımlı şap betonu uygulamalarında öncelikle genleştirilmiş perlit agregalarının, daha sonra ise genleştirilmiş cam agregalarının tercih edilmesi uygun olacaktır.

Tablo 8. Genleştirilmiş cam agregalı şap harçlarına ait yoğunluk, ses yutma katsayısı ve ısıl iletkenlik değeri deney sonuçları

\begin{tabular}{lcccc}
\hline Numune & $\begin{array}{c}\text { TS EN 13813 (2004) [24] } \\
\text { Kisa Gösterim }\end{array}$ & $\begin{array}{c}\text { Yoğunluk } \\
\left(\mathbf{g} / \mathbf{c m}^{\mathbf{3}}\right)\end{array}$ & $\begin{array}{c}\text { Ses Yutma } \\
\text { Katsayısı }\end{array}$ & $\begin{array}{c}\text { Isil İletkenlik Değeri } \\
\text { (W/Mk) }\end{array}$ \\
\hline CIB & CT-C50-F8-A10 & 2.157 & 0.159 & 0.781 \\
CIB15EG & CT-C45-F7-A12 & 1.950 & 0.197 & 0.652 \\
CIB30EG & CT-C38-F6-A14 & 1.742 & 0.224 & 0.571 \\
CIC & CT-C58-F11-A9 & 2.192 & 0.151 & 0.817 \\
CIC15EG & CT-C48-F10-A11 & 1.983 & 0.172 & 0.717 \\
CIC30EG & CT-C41-F10-A13 & 1.770 & 0.218 & 0.603 \\
& & & & \\
CIIB & CT-C50-F7-A11 & 2.149 & 0.172 & 0.732 \\
CIIB15EG & CT-C43-F7-A12 & 1.942 & 0.201 & 0.644 \\
CIIB30EG & CT-C37-F6-A14 & 1.737 & 0.225 & 0.570 \\
CIVA & CT-C37-F4-A14 & 2.084 & 0.187 & 0.722 \\
CIVA15EG & CT-C28-F4-A15 & 1.878 & 0.210 & 0.608 \\
CIVA30EG & CT-C20-F4-A16 & 1.683 & 0.241 & 0.467 \\
\hline
\end{tabular}

Tablo 9. Genleştirilmiş perlit agregalı şap harçlarına ait yoğunluk, ses yutma katsayısı ve 1sıl iletkenlik değeri deney sonuçları

\begin{tabular}{lcccc}
\hline Numune & $\begin{array}{c}\text { TS EN 13813 (2004) [24] } \\
\text { Kisa Gösterim }\end{array}$ & $\begin{array}{c}\text { Yoğunluk } \\
\left(\mathbf{g} / \mathbf{c m}^{\mathbf{3}}\right)\end{array}$ & $\begin{array}{c}\text { Ses Yutma } \\
\text { Katsayısı }\end{array}$ & $\begin{array}{c}\text { Isıl İletkenlik Değeri } \\
\text { (W/Mk) }\end{array}$ \\
\hline CIB & CT-C50-F8-A10 & 2.157 & 0.159 & 0.781 \\
CIB15EP & CT-C42-F7-A13 & 1.931 & 0.207 & 0.614 \\
CIB30EP & CT-C35-F6-A14 & 1.718 & 0.239 & 0.501 \\
& & & & \\
CIC & CT-C58-F11-A9 & 2.192 & 0.151 & 0.817 \\
CIC15EP & CT-C44-F10-A11 & 1.975 & 0.187 & 0.699 \\
CIC30EP & CT-C38-F10-A13 & 1.763 & 0.220 & 0.590 \\
& & & & \\
CIIB & CT-C50-F7-A11 & 2.149 & 0.172 & 0.732 \\
CIIB15EP & CT-C42-F6-A13 & 1.937 & 0.205 & 0.634 \\
CIIB30EP & CT-C34-F6-A14 & 1.722 & 0.235 & 0.570 \\
CIVA & CT-C37-F4-A14 & 2.084 & 0.187 & 0.722 \\
CIVA15EP & CT-C26-F4-A15 & 1.876 & 0.215 & 0.605 \\
CIVA30EP & CT-C17-F4-A17 & 1.669 & 0.249 & 0.446 \\
\hline
\end{tabular}

\section{Sonuç ve Öneriler}

Bu çalışmada inşaat sektöründe yüzey kaplama ve tesviye amacı ile en çok kullanılan şap harcının özelliklerini iyileştirmek için, genleştirilmiş cam agregası ve genleştirilmiş perlit agregası, şap harc1 bileşeni olarak kullanılmış ve bu şekilde şap harcı malzemesinin eğilme dayanımı, basınç dayanımı ve aşınma direnci özelliklerinin arttırılmasına ek olarak birim hacim ağırlığının azaltılması, 1sı ve ses izolasyon performanslarının arttırılması hedeflenmiştir. Elde edilen bilgiler ışığında, 
genleştirilmiş cam ve genleştirilmiş perlitin; yapıların ağırlığını azaltma, termal özelliklerini iyileştirme gibi performans arttırıcı özelliklerinden dolayı, CEN standart kum yerine ikame edilerek şap harcı üretiminde sürdürülebilir yapı malzemesi olarak kullanılmasının faydalı olacağı sonucuna ulaşılmıştır. Genleştirilmiş cam ve genleştirilmiş perlit malzemesinin performans özellikleri karşılaştırıldığında ise; mukavemetin önem kazandığ 1 yerlerde genleştirilmiş camın, hafifliğin önem kazandığı yerlerde ise genleştirilmiş perlitin tercih edilmesi uygun olacaktır. Bununla birlikte genleştirilmiş cam agregalı şap harçlarının tercih edilmesi, atık camların çevreye verdiği zararı kısmen de olsa azaltabilir. Ayrıca konu ile ilgili çalışmaların; sıva harcı, beton, hafif beton, kendiliğinden yerleşen beton, püskürtme beton gibi diğer özel betonlarla sürdürülmesinin faydalı olacağı düşünülmektedir.

\section{Teşekkür}

118M111 kodlu bu proje, TÜBİTAK tarafından desteklenmiştir. Bu çalışmanın ortaya çıkmasında verdiği destekten ötürü TÜBİTAK'a ve katkılarından dolayı Göltaş Çimento A.Ş' ye teşekkür ederiz.

\section{Kaynaklar}

[1]. Altuncı Y. T., “Genleştirilmiş Cam Agregalı ve Genleştirilmiş Perlit Agregalı Şap Harçlarının Performans Özellikleri’, Doktora Tezi, Süleyman Demirel Üniversitesi Fen Bilimleri Enstitüsü, Isparta, 2019.

[2]. Çalışkan Ş., “Türkiye'nin Enerjide Dışa Bağımlılık Ve Enerji Arz Güvenliği Sorunu’, Dumlupınar Üniversitesi Sosyal Bilimler Dergisi, 2009, 25, 297-310.

[3]. Alcan Y., Demir M., Duman S., "Sinop İlinin Güneş Enerjisinden Elektrik Üretim Potansiyelinin Ülkemiz Ve Almanya İle Karşılaştırarak İncelenmesi', El-Cezerî Fen ve Mühendislik Dergisi, 2018, 5(1): 35-44.

[4]. Resmi Gazete. Yönetmelik. http://www.resmigazete.gov.tr/eskiler/2008/12/20081205-9.htm (Erişim Tarihi: 18.01.2019).

[5]. Resmi Gazete. Yönetmelik. http://www.resmigazete.gov.tr/eskiler/2017/05/20170531-7.htm (Erişim Tarihi: 18.01.2019).

[6]. Winworld. IZODER Açılama. http://www.winworld.net/haberler/1-haziranda-yururlugegiren-iki-yeni-yonetmelikle-binalarda-su-ve-ses-yalitimi-zorunlu-oldu.html (Eriş. Tarihi: 18.01.2019).

[7]. Kralj D., "Experimental Study of Recycling Lightweight Concrete with Aggregates Containing Expanded Glass"', Process Safety and Environmental Protection, 2009, 87(4), 267-273.

[8]. Nemes R., Józsa Z., "Strength of Lightweight Glass Aggregate Concrete”, Journal of Materials in Civil Engineering, 2006, 710-714.

[9]. Bumanis G., Bajare D., Korjakins A., "Mechanical and Thermal Properties of Lightweight Concrete Made from Expanded Glass", Journal of Sustainable Architecture And Civil Engineering, 2013, 2(3), 26-32.

[10]. Carsana M., Bertolini L., "Durability of Lightweight Concrete with Expanded Glass and Silica Fume'”, ACI Materials Journal, 2017, 207-213.

[11]. Keskin F.Ş., Yıldırım S.T., “Taguchi Metoduyla Deneysel Tasarım Kullanarak Yalıtımlı Harç İçin Perlit ve Taban Külü Kullanılabilirliğinin Araştırılması, El-Cezerî Fen ve Mühendislik Dergisi, 2016, 3(1): 91-102.

[12]. Perhabbe. Genleştiriliș Cam Bilgi. http://www.perhabbe.com/perHAbbe\%C2\%AEGenlesmisCam,s4.html (Erişim Tarihi: 19.01.2019).

[13]. ASCE. Suda Batmayan Beton Bilgi. https://www.infrastructurereportcard.org/ (Erişim Tarihi: 18.01.2019). 
[14]. ITUMHK. Suda Batmayan Beton Kano. http://www.itumhk.com/ (Erişim Tarihi: 18.01.2019).

[15]. Misapor. Teknik Bilgi. http://www.misapor.ch/en (Erişim Tarihi: 18.01.2019).

[16]. Liaver. Teknik Bilgi. http://www.liaver.com/reapor/ (Erişim Tarihi: 18.01.2019).

[17]. Poraver. Teknik Bilgi. http://www.poraver.com/en/poraver/ (Erişim Tarihi: 18.01.2019).

[18]. Stikloporas. Teknik Bilgi. http://www.stikloporas.lt/Produktas/Savybes (Erişim Tarihi: 18.01.2019).

[19]. Yu, R., Onna, D. V., Spiesz, P., Yu, Q. L., Brouvers, H. J. H., “'Development of UltraLightweight Fibre Reinforced Concrete Applying Waste Glass', Jornal of Cleaner Production, 2016, 112, 690-701.

[20]. Ismail, Z. Z., Al-Hashmi, E. A., "Recycling of Waste Glass as a Partial Replacement for Fine Aggregate in Concrete', Waste Management, 2009, 29(2), 655-659.

[21]. Rashad A. M., "Recycled Waste Glass as Fine Aggregate Replacement in Cementitious Materials Based on Portland Cement', Construction and Building Materials, 2014, 72, 340357.

[22]. Ultraper. Teknik Bilgi. http://www.ultraper.com/-page id=32.htm (Erişim Tarihi: 18.01.2019).

[23]. TS EN 13892-1, “Şap Malzemeleri - Deney Metotları - Bölüm 1: Deneyler için Numune Alma, Hazırlama ve Kürleme'”, Türk Standartları Enstitüsü, Ankara, 2004.

[24]. TS EN 13813, “Şap Malzemeleri ve Zemine Uygulanan Şaplar - Şap Malzemeleri Özellikler ve Gerekler', Türk Standartları Enstitüsü, Ankara, 2004.

[25]. Göltaş. Teknik Bilgi. http://www.Goltas.com.tr/files/urunlerimiz/dgjrapsb6jsoc0c0kg.pdf (Erişim Tarihi: 19.01.2019).

[26]. Göltaş. Teknik Bilgi. http://www.Goltas.com.tr/files/urunlerimiz/2n6ovha9ftkws88ggg.pdf (Erişim Tarihi: 19.01.2019).

[27]. Göltaş. Teknik Bilgi. http://www.Goltas.com.tr/files/urunlerimiz/pwnnb8yfadcwk4coc4.pdf (Erişim Tarihi: 19.01.2019).

[28]. Göltaş. Teknik Bilgi. http://www.Goltas.com.tr/files/urunlerimiz/b9cpybnmq74g0og8sk.pdf (Erişim Tarihi: 19.01.2019).

[29]. Perhabbe. Teknik Bilgi. http://www.perhabbe.com/Teknik-Bilgiler,s11.html (Erişim Tarihi: 19.01.2019).

[30]. TS EN 196-1, “Çimento Deney Metotları - Bölüm 1: Dayanım tayini”, Türk Standartları Enstitüsü, Ankara, 2016.

[31]. TS EN 13892-3, “Şap Malzemeleri - Deney Metotları - Bölüm 2: Aşınma Direncinin Tayini - Böhme', Türk Standartları Enstitüsü, Ankara, 2015.

[32]. TS EN 12390-7, “Beton - Sertleşmiş Beton Deneyleri - Bölüm 7:Sertleşmiş Beton Yoğunluğunun Tayini',, Türk Standartları Enstitüsü, Ankara, 2010.

[33]. TS EN ISO 10534-1, “Akustik- Empedans Borularında Ses Absorplama Katsayıs1 ve Empedansın Tayini - Bölüm 1: Duran Dalga Oranını Kullanma Metodu', Türk Standartları Enstitüsü, Ankara, 2004.

[34]. TS EN ISO 10534-2, “Akustik-Empedans Borularındaki Ses Absorpsiyon Katsayısının Ve Empedansın Tayini-Bölüm 2: Aktarım Fonksiyonu Metodu’, Türk Standartları Enstitüsü, Ankara, 2003.

[35]. TS EN 12664, "Yapı Malzemeleri Ve Mamulleri - Isıl Direncin, Korumalı Tablalı Isitıcı ve Isı Akı Ölçerin Kullanıldığı Metotlarla Tayini - Isıl Direnci Orta Ve Düşük Seviyede Olan Kuru Ve Rutubetli Mamuller', Türk Standartları Enstitüsü, Ankara, 2009.

[36]. Kılıç, F. M., “Hafif Şap ile Normal Şap Uygulamasının Karşılaştırılması’, Yüksek Lisans Tezi, Erciyes Üniversitesi Fen Bilimleri Enstitüsü, Kayseri, 2018.

[37]. Balun, B., "Hafif Agregalı Kendiliğinden Yerleşen Harçların Mekanik ve Durabilite Özellikleri’, Yüksek Lisans Tezi, Fırat Üniversitesi Fen Bilimleri Enstitüsü, Elazı̆̆g, 2013. 
[38]. Demirboğa, R., Gül, R., Örüng, İ., “Effects Of Expanded Perlite Aggregate And Mineral Admixtures On The Compressive Strength Of Low- Density Concretes', Cement and Concrete Research, 2001, 31, 1627-1632.

[39]. Demirboğa, R., Gül, R., "The Effects Of Expanded Perlite Aggregate, Silica Fume And Fly Ash On The Thermal Conductivity Of Lightweight Concrete", Cement and Concrete Research, 2003, 33, 723-727.

[40]. Clarke, J. L., 'Structural Lightweight Aggregate Concrete', Blackie Academic \& Professional, 1993, London. 